\title{
Como o acúmulo de Atividades Administrativas no Colegiado Acadêmico de Ciências da Natureza da UNIVASF Campus Senhor do Bonfim - BA interfere na Produtividade do Servidor: Um Estudo de Caso
}

\author{
Hesler Piedade Caffé Filho ${ }^{1}$; Jairo dos Santos Souza ${ }^{2}$; Ricardo de Santana Amorim ${ }^{3}$
}

Resumo: O presente trabalho faz um estudo de como o acumulo de atividades administrativas podem interferir na qualidade e produtividade do servidor público federal. O estudo foi realizado no Colegiado Acadêmico de Ciências da Natureza da Universidade Federal do Vale do São Francisco - Univasf, no Campus de Senhor do Bonfim - BA. A partir da análise dos dados que foram coletados, foi possível verificar o que estava acarretando $\mathrm{o}$ acúmulo de atividades administrativas.

Palavras-chave: Acúmulo de atividades. Servidor público. Stress. Produtividade.

\section{How the accumulation of Administrative Activities in the Academic Collegiate of Nature Sciences of UNIVASF Campus Senhor do Bonfim in Bahia interferes in Server Productivity: A Case Study}

\begin{abstract}
The present work makes a study of how the accumulation of administrative activities can interfere in the quality and productivity of the federal public servant. The study was carried out at the Academic College of Nature Sciences of the Federal University of the São Francisco Valley - Univasf, at the Campus of Senhor do Bonfim - BA. From the analysis of the data that were collected, it was possible to verify what was causing the accumulation of administrative activities.
\end{abstract}

Keywords: activities accumulation. Public server. Stress. Productivity.

\section{Introdução}

A sociedade contemporânea é marcada pela correria do dia-a-dia e pela constante mudança de cenários. Essas mudanças ocorrem em ritmo acelerado e é preciso estar para a adaptar-se a todo o momento, como um verdadeiro camaleão. Diariamente, o homem enfrenta novos desafios e estabelece novas prioridades.

\footnotetext{
${ }^{1}$ Mestrado Profissional em Mestrado em Gestão de Políticas Públicas pela Universidade Federal do Recôncavo da Bahia, Brasil(2016) Professor de Pós Graduação EaD da Universidade Federal do Vale do São Francisco, Brasil. E-mail: hesler.caffe@univasf.edu.br; ${ }^{2}$ Universidade Federal do Vale do São Francisco (UNIVASF);

${ }^{3}$ Universidade Federal do Vale do São Francisco (UNIVASF). Autor correspondente: ricardoamoorim@gmail.com
} 
Contudo, as constantes conturbações impedem o alcance das metas estabelecidas, nem todas as atividades determinadas como prioritárias para aquele dia são cumpridas e é gerada uma sensação de que se possui pouco tempo para fazer tudo que necessário e desejado.

O homem se encontra cada vez mais pressionado pelo relógio. Os prazos são muito curtos e o número atividades crescentes. O ritmo social e o fluxo informacional são muito intensos, havendo um excesso de informação a circular pelo mundo, acessível a todos pelo advento da internet. Cria-se, contanto, uma nova necessidade: a de se estar ciente de tudo o que está acontecendo a todo o momento.

Este Trabalho de Conclusão de Curso objetiva traçar considerações relevantes acerca do tema "acúmulo de atividades administrativas", destacando os motivos que acarretam o acúmulo de atividades, tudo isso através do estudo de caso específico no Colegiado Acadêmico de Ciências da Natureza - Univasf, situada em Senhor do Bonfim - BA.

Nesse contexto, pode-se desde já afirmar que o acúmulo de atividades adminstrativas, interfere na produtividade do servidor público, o que consequentemente fará com que não conclua suas atividades em tempo hábil, resutando em stress e protelação.

O exercício do trabalho, segundo JÚNIOR (1996), marca acentuadamente a existência humana, pois o mesmo está presente, pelo menos, em um terço do dia, porém refletindo em todos os seus momentos filósofos, teólogos, cientistas, políticos, engenheiros, profissionais da área de saúde e, principalmente, o médico de trabalho e sua equipe, estão engajados na transformação progressiva da dinâmica das frentes de trabalho, revendo a sua organização, suas condições, processos de execução com suas respectivas tecnologias, na tentativa de resgatá-lo do seu sentido maior da vida: o engrandecimento do ser humano.

Sendo assim, neste TCC serão abordados conceitos relevantes pertinentes ao tema. Cumpre ressaltar que esta pesquisa visa deixar evidente que o acumulo de atividades administrativas nas intituições públicas devem ser analisada criteriosamente, sendo importante realizar uma pesquisa na bibliografia contemporânea acerca do tema acúmulo de atividades administrativas, visando destacar seus efeitos para com o servidor, bem como também realizar um estudo de caso para comprovar as consequências que o acúmulo de atividades pode trazer para o servidor. 
A seguir, inicia-se a contextualização do estudo, na qual é possível verificar o tema, questão, objetivos e justificativa que deram direcionamento à realização do mesmo.

\section{Justificativa}

Tem-se que a escolha do tema "acúlumo de atividades administrativas" para pesquisa se justifica justamente em virtude da relevância que o assunto tem com o trabalho do servidor público, que às vezes são acometidos pela falta de instrumentos de gestão adequado, juntamente com a grande decadência das condições de trabalho atual, que os serviços públicos são expostos.

É importante esclarecer que a temática se constitui de uma questão do tempo cotemporaneo, estando vivenciadas nas organizações públicas, neste sentido, este trabalho busca colaborar para a excelência dos serviços públicos prestados a sociedade.

\section{Objetivo Geral}

Compreender como o acúmulo de atividades administrativas no Colegiado Acadêmico de Ciências da Natureza da Univasf Campus Senhor do Bonfim - BA interfere na produtividade do servidor.

\section{Objetivos Especificos}

- Quantificar as demandas administrativas que chegam ao colegiado acadêmico;

- Entender como ocorre à divisão de tarefas considerando a jornada de trabalho do servidor;

- Ampliar o entendimento sobre as questões administrativas e laborais que permeiam os trabalhos de um Técnico Administrativo Educacional. 


\section{Metodologia}

A pesquisa utilizou-se da técnica do estudo de caso, visando analisar uma situação com maior profundidade. O caso foi levantado no Colegiado Acadêmico de Ciências da Natureza da Universidade Federal do Vale do São Francisco - Univasf, no Campus de Senhor do Bonfim - BA.

De acordo com Gil (1991), o estudo de caso é caracterizado pelo estudo exaustivo e em profundidade de poucos objetos, de forma a permitir conhecimento amplo e específico do mesmo; tarefa praticamente impossível mediante os outros delineamentos considerados.

\section{Tipo de Pesquisa}

A metodologia deste estudo foi realizada por meio de uma pesquisa exploratória, já que foi nescessário adquirir conhecimento com base no levantamento bibliográfico sobre os conceitos envolvidos no tema apresentado, de forma que viesse a proporcionar maior compreensão do fenômeno investigado.

\footnotetext{
"A pesquisa explotatória visa prover o pesquisador de um maior conhecimento sobre o tema ou problema de pesquisa em perspectiva. Por isso, é apropriada para os primeiros estágios da investigação quando familiaridade, o conhecimento e a compreensão do fenômeno por parte do pesquisador são, geralmente, insuficientes ou inexistentes." (MATTAR,1999, p. 80)
}

Segundo Gil (1999), a pesquisa exploratória é realizada especialmente quando o tema escolhido é pouco explorado, existe pouco conhecimento sistematizado e acumulado na área em que o trabalho foi realizado. Considerando-se a pequena produção de pesquisa que envolve servidores e organizações públicas, enquadra-se esta pesquisa como exploratória.

Também para Vergara (1997) a pesquisa exploratória é aquela na qual existe pouco conhecimento sistematizado e acumulado na área em que o trabalho foi realizado, e permite ao investigador aumentar sua experiência em torno do problema em questão. 
O estudo foi conduzido inicialmente através de consulta à bibliografia, dando ênfase ao aspecto teórico, revisão da literatura acerca do assunto escolhido e o convívio no ambiente em estudo para posterior elaboração de uma entrevista semi-estruturada, com o objetivo de explorar o tema.

Dentro da organização escolhida, a Universidade Federal do Vale do São Francisco Univasf, no Campus de Senhor do Bonfim - BA, a investigação foi desenvolvida em somente um de seus três colegiados, o Colegiado Acadêmico de Ciências da Natureza.

\section{Coleta de Dados}

Inicialmente, após a definição dos objetivos da pesquisa, foi realizado um levantamento teórico com a revisão bibliográfica sobre o tema apresentado, com o intuito de fornecer dados para subsidiar a análise dos resultados.

A coleta de dados para efeito desta pesquisa se deu por meio de entrevista e observacão durante cinco meses no Colegiado de Ciências da Natureza, o que permitiu estudá-lo com maior profundidade e examinar seu ambiente detalhadamente.

Primeiramente utilizou-se durante a pesquisa a técnica da observação direta e sistemática, que agrega valor à análise dos dados da fala dos sujeitos, o que, segundo Marconi e Lakatos (2008, p. 78) permite ao observador maior objetividade e diminui sua influência sobre o que vê ou recolhe, uma vez que o observador sabe o que procura e o que carece de importância em determinada situação.

Além da observação foi aplicada entrevista semi-estruturada junto ao servidor administrativo do Colegiado Acadêmico de Ciências da Natureza, com um roteiro de questões predefinidas.

Para Triviños (1987), a entrevista semi-estruturada é um dos principais meios que o investigador tem para realizar a coleta de dados. Pode-se entender como aquela que parte de certos questionamentos básicos, apoiados em teorias e hipóteses, e que em seguida, oferecem amplo campo de interrogativas, frutos de novas hipóteses que vão surgindo à medida que se recebem as respostas do informante.

Assim, o roteiro da entrevista teve a seguinte ordem e questões:

- Como você avalia suas condições de trabalho? 
- Quais as dificuldades enfrentadas na realização do seu trabalho?

- Você se sente sobrecarregado no seu trabalho?

- Como você distribui a carga horária no decorrer do seu trabalho?

- Você se considera motivado para trabalhar no Colegiado?

Procurou-se fazer com que o entrevistado chegasse aos questionamentos que mais interessavam ao estudo através de perguntas que indicassem o caminho a ser percorrido, com a mínima interferência por parte do entrevistador, deixando a palavra livre ao entrevistado, retomando somente quando necessário.

\section{Gestão Pública}

Para Abrucio (1999), no âmbito mundial, a gestão pública encontra-se num contexto revolucionário, isto é, passa por alterações no modelo burocrático. Segundo Bresser Pereira (1999), a gestão pública ainda se norteia pela administração burocrática, cujo modelo foi implantado, nos principais países europeus, no final do século XIX, nos Estados Unidos, no início do século XX e no Brasil, em 1936.

Secchi (2009) relata que ocorreram mudanças importantes nas políticas de gestão pública nas administrações públicas mundiais, a partir dos anos 1980. Neste contexto, dois modelos gerenciais pós-burocráticos, baseados em valores de eficiência, eficácia e competitividade são apresentados para substituir o modelo burocrático de Max Weber: a Administração Pública Gerencial (APG) e o Governo Empreendedor (GE).

Os modelos de APG e GE levam em conta a liberdade de decisão dos gerentes e consideram os cidadãos como clientes. Já no modelo burocrático, o cidadão é tratado como usuário (SECCHI, 2009).

A Nova Administração Pública abordada por Hood (1998) pregava conceitos mais modernos de gestão, onde há preocupação com planejamento, produtividade e resultados, a fim de responder com eficácia às demandas da sociedade.

No Brasil, a Nova Gestão Pública equivale à Administração Pública Gerencial (APG), diferenciada pelo uso das práticas gerenciais com foco na descentralização, delegação de 
autoridade, eficácia, planejamento, organização, liderança e controle sobre o desempenho. A função pública tem o dever de oferecer à sociedade um serviço público de qualidade, com redução de tempo e de custos (DI GIACOMO, 2005).

A administração pública pode assumir duas vertentes principais: a primeira baseia-se na ideia de servir e executar e a segunda envolvem os conceitos de gerência ou gestão. No entanto, a administração pública caracteriza-se pela relação de subordinação e hierarquia (CASELLA, 2008).

Nos últimos anos, esforços foram direcionados no sentido de estabelecer alternativas de gestão efetivamente voltadas para o setor público, embora a maioria das ferramentas disponíveis seja concebida sob a visão dos objetivos do setor privado, basicamente distintos dos objetivos do Estado (PAES DE PAULA, 2005).

Percebe-se que a estratégia da administração pública gerencial volta-se para:

i) a definição dos objetivos que o administrador público deverá atingir em sua unidade;

ii) a garantia de autonomia do administrador na gestão dos recursos humanos, materiais e financeiros que lhe forem colocados à disposição para que possa atingir os objetivos contratados; e

iii) o controle ou cobrança a posteriori dos resultados. Em suma, afirma-se que a administração pública deve ser permeável à maior participação dos agentes privados e/ou das organizações da sociedade civil e deslocar a ênfase dos procedimentos para os resultados (BRASIL, 1995).

Dentro da estrutura de Estado, Osório (2005) diz que a gestão pública tem assumido um gerenciamento mais eficaz das obras públicas, graças à utilização de práticas inovadoras de gestão de projetos. No âmbito da administração estadual, essa inovação se torna um desafio pertinente a fatores decisivos como eleições, sucessão de governos, mudança da equipe de gestores para governos locais aliados e oferta de cargos mais bem remunerados em outros órgãos, já que a rotatividade de pessoas é inerente aos governos e ao próprio processo eleitoral (ZOGHBI; MARTINS, 2009). 


\section{OSM e Administração Científica - Estudos de Tempos e Movimentos}

Viver e trabalhar em uma sociedade global é um grande desafio para todos os cidadãos. A busca por tecnologia, informação, conhecimento de qualidade, novas habilidades para liderança e solução de problemas com eficiência tornou-se uma questão de sobrevivência no mundo do trabalho. Cada um de nós tem uma grande responsabilidade: as escolhas que fizermos por nós e pelos nossos fará grande diferença no futuro.

O conceito de organização dentro do campo administrativo é de gerir capital, recursos humanos, equipamentos e processos com o objetivo de se atingir um determinado resultado.

Para Tadeu Cruz (2002), OSM é o estudo das organizações por meio da análise de cada uma das atividades, a fim de criar procedimentos que venham a interligá-las de forma sistêmica. Segundo Maximiano (2008), o termo ORGANIZAÇÃO é um sistema de recursos que procura realizar algum tipo de objetivo. Para Rocha (1998), define OSM como sendo a função mista de Organização e Planejamento, desenvolvendo-se na construção da estrutura de recursos e de operações de uma instituição, na determinação dos planos, principalmente na definição dos procedimentos, rotinas e métodos.

$\mathrm{Na}$ administração científica temos o americano Frederick Winslow Taylor como criador, com intuito de garantir o melhor custo/benefício aos sistemas produtivos. Anteriormente à proposta de Taylor, os antigos sistemas de administração de empresas impunham a cada trabalhador a responsabilidade de executar o trabalho da maneira que lhes conviessem. De mais a mais, também cabia ao trabalhador à escolha do instrumento de trabalho, dentre os vários à disposição. Nesse sentido, não havia quase nenhuma orientação por parte da gerência (TAYLOR, 1990). Diante do exposto, o panorama encontrado em meados do século XIX era o de quase nenhuma uniformidade quanto à forma de se fazer determinado ofício.

O estudo de tempos e movimentos é uma ferramenta de extrema importância nas funções de uma empresa, visando à diminuição do tempo desnecessário perdido entre as ações, e visando também um melhor aproveitamento do tempo e dos movimentos exercidos por cada trabalhador em suas funções. Seu inicio foi na primeira metade do século passado, e 
era aplicada apenas em organizações do tipo industrial. Seus precursores foram Frederick W. Taylor e o casal Frank e Lílian Gilbreth.

O desenvolvimento e a utilização que Taylor deu a cronometragem foi uma de suas principais contribuições. Segundo suas palavras: "o estudo de tempos é um dos elementos da administração científica que torna possível transferir-se a habilidade da administração da empresa para os funcionários." (BARNES, 1977).

Frank B. Gilbreth e sua esposa Lillian M. Gilbreth desenvolveram diversos trabalhos observando o fator humano e conhecimentos técnicos, bem como o conhecimento de materiais, ferramentas e equipamentos. Apesar de Taylor e Gilbreth terem desenvolvido o seu projeto pioneiro na mesma época, deu-se mais ênfase ao estudo de tempos. Somente em 1930 que iniciou o estudo do trabalho com o objetivo de descobrir métodos melhores e mais simples de se executar uma tarefa. Desde então, os dois estudos passaram a se completar e serem utilizados em conjunto. (BARNES, 1977)

Segundo PEINADO \& GRAEML (2007, p. 86) O estudo de tempos, movimentos e métodos aborda técnicas que submetem a uma detalhada análise de cada operação de uma dada tarefa, com o objetivo de eliminar qualquer elemento desnecessário à operação e determinar o melhor e mais eficiente método para executá-la.

O estudo de tempos e movimentos tem como objetivo, segundo BARNES (1977):

(1) desenvolver o sistema e o método preferido, usualmente aquele de menor custo; (2) padronizar esse sistema e método; (3) determinar o tempo gasto para uma pessoa qualificada e devidamente treinada, trabalhando num ritmo normal, para executar uma tarefa ou operação específica; (4) orientar o treinamento do trabalhador no método preferido.

O desenvolvimento do método "ideal" ou preferido parte em primeiro lugar da definição do problema, o qual visa à elaboração do relatório geral composto por metas e objetivos. Em seguida será realizada a análise do problema, onde ocorrerá neste momento a descrição do método além de determinar as especificações e restrições. Ao serem identificadas as possíveis soluções, será realizada uma avaliação objetivando determinar o método que proporcionará menor custo e certamente menor investimento, contribuindo assim para a implementação mais rápida no processo produtivo, método este que possibilite melhor qualidade e menores perdas. A utilização desta metodologia torna-se possível projetar um 
sequenciamento de operações que mais se aproximem da solução ideal. (FIGUEIREDO; OLIVEIRA; SANTOS, 2011)

Depois de ter sido encontrado o melhor método de se executar uma operação, esse método deve ser padronizado. Normalmente, a tarefa é dividida em trabalhos ou operações específicos. O conjunto de movimentos do operador, as dimensões, a forma e a qualidade do material, as ferramentas, os dispositivos, os gabaritos, os calibres e o equipamento, deverem ser especificados com clareza. Todos esses fatores, bem como as condições de trabalho do operador, precisam ser conservados depois de haver sido padronizado. Um registro de método padronizado de operação fornecendo descrição detalhada da operação e das especificações para execução da tarefa é a maneira mais comum de preservarem-se os padrões. (BARNES, 1977).

Após ter sido padronizada a operação o passo seguinte será a determinação do tempo padrão, o mesmo visa identificar o tempo que o operador qualificado e treinado deveria gastar para executar certa operação. Com a coleta destes dados torna-se possível fazer um planejamento e uma programação a qual estimara o custo da mão-de-obra a ser utilizada, ferramenta base para incentivos salariais e ainda como planejamento e controle da produção. E para finalizar o estudo dos tempos e de movimentos o treinamento do operador é de grande relevância para que o operador possa executar suas operações sem maiores dificuldades. (FIGUEIREDO; OLIVEIRA; SANTOS, 2011).

Uma das decorrências do estudo dos tempos e movimentos foi a divisão do trabalho e a especialização do operário a fim de elevar sua produtividade. Com isso, cada operário passou a ser especializado na execução de uma única tarefa para ajustar- se aos padrões descritos e às normas de desempenho definidas pelo método. $\mathrm{O}$ trabalho é executado melhor $\mathrm{e}$ mais economicamente por meio da análise do trabalho, isto é, da divisão e subdivisão de todos os movimentos necessários à execução de cada operação de uma tarefa. Observando metodicamente a execução de cada operação a cargo dos operários. (CHIAVENATO, 2004).

Hoje em dia muitas das grandes empresas enfrentam problemas causados por operários que executam a mesma tarefa de forma diferente. Nesse caso padronizar os processos, definindo e discutindo a melhor forma de realizá-lo, treinando os operários e assegurando a execução das tarefas conforme o definido é o melhor método para aumentar a produtividade de cada funcionário eliminando das suas operações possíveis perdas. A padronização das 
atividades é a base para o planejamento e controle da produção que tem o objetivo de atender a uma demanda determinada e simultaneamente maximizar o lucro da empresa.

Deste modo, a padronização das operações e o conhecimento acurado da capacidade produtiva têm influência direta na eficácia do PCP (Planejamento e Controle da Produção) pelo alcance de alguns de seus objetivos como: redução dos lead times de produção, possibilidade de cumprimento de prazos e agilidade de resposta diante de alterações de demanda. (PICANCO; FRANCA; CRUZ; SANTOS, 2011).

\section{A Gestão de Pessoas}

As pessoas constituem o mais importante ativo das organizações. Este contexto é representado íntima interdependência das organizações e das pessoas. O relacionamento entre ambos, antes considerados conflitos, hoje é baseada na solução do tipo ganha - ganha, onde cada uma das partes tem seus objetivos. A Gestão de Pessoas depende da mentalidade predominante na organização.

Atualmente as organizações estenderam seus conceitos de parceria, incluindo nele os funcionários. Cada parceiro está disposto a investir seus recursos na organização na medida em que obtiver retornos adequados. Assim as pessoas deixaram de ser considerados recursos, para serem tratadas como parceiras. Os objetivos da Gestão de pessoas passaram a ser estratégicos e os seus processos são: agregar, aplicar, recompensar, manter, desenvolver e monitorar pessoas. Contudo a Gestão de Pessoas é uma responsabilidade de linha e uma função de staff (que toma as decisões peculiares da linha), o que requer compartilhamento entre os especialistas de RH e Gerentes de linha (CHIAVENATO, 2008, p. 29-31).

\section{Resultados Encontrados}

Após coletados todos os dados para o desenvolvimento do trabalho, foram analisados e interpretados, a fim de conseguir respostas ao problema proposto. 
Yin (2005) afirma que não importa qual a estratégia, mas a análise deve ser sempre de alta qualidade, devendo basear-se, pelo menos em quatro princípios: deixar claro que baseouse em todas as evidências, análise deve abranger todas as principais interpretações concorrentes; deve dedicar-se aos aspectos mais significativos do estudo; o pesquisador deve fazer uso de seu conhecimento prévio.

A pesquisa buscou interpretar os dados, e correlacionar informações obtidas na pesquisa de campo com as evidenciadas no referencial teórico.

Durante a observação foi possível verificar algumas atividades do assistente administrativo do colegiado, como: atender os docentes e dicentes, fornecendo e recebendo informações; tratando de documentos variados, cumprindo todo o procedimento necessário referente aos mesmos; executando serviços gerais de escritório.

Dentre os documentos utilizados pelo Assistente Administrativo, estão memorandos e ofícios, que após confeccionados, o Assistente Administrativo cria o mesmo documento no Sistema de Tramitação de Documentos, denominado STD, onde é anexada cópia digitalizada do documento e enviado ao setor de destino pelo sistema e, posteriormente, encaminhado o documento físico.

No colegiado ocorrem reuniões ordinariamente, pelo menos uma vez por mês, e extraordinariamente, sempre que convocado pela Coordenação do Colegiado. Para as reuniões ordinárias é elaborado um calendário semestral e a convocação deve ser com antecedência mínima de 48 horas, já a convocação da reunião extraordinária pode ocorrer a qualquer momento. Além das reuniões do colegiado, ocorrem também reuniões ordinárias do Núcleo Docente Estruturante - NDE.

Após a realização da reunião, é digitada a ata com auxílio do áudio da reunião, e enviada a todos os membros para aprovação, podendo desde o seu recebimento, encaminharem as sugestões de alteração de forma a otimizar a sua aprovação no dia da reunião seguinte.

No colegiado são recebidos diariamente requerimentos gerais. Esses requerimentos são preenchidos com a solicitação do aluno e entregas no SIC que é o setor responsável por receber, registrar e responder os pedidos de acesso à informação. Em seguida o requerimento é enviado para o colegiado. 
A cada final de semestre o Departamento de Registro e Controle Acadêmico - DRCA envia para o colegiado os processos de desligamentos de cada discente, que por motivo de cancelamento voluntário de vinculo ou ato administrativo não se apresentaram à instituição.

Os diários de classes das disciplinas dos docentes são confeccionados no colegiado no início de cada semestre, contendo: programa de disciplina, caderneta de atividades, com a descrição dos conteúdos ministrados ao longo do semestre; Mapa de notas e frequências extraído do Sistema de Informação e Gestão Acadêmica da Univasf; Relatório de controle diário de frequência de estudantes. Após o encerramento do semestre letivo, o colegiado providência o envio dos diários para a Secretaria de Registro e Controle Acadêmico (SRCA) para arquivamento.

Após as observações citadas acima e a entrevista, foi possivel perceber o que estava acarretando o acumulo de atividades no colegiado. Abaixo segue as principais causas:

1. Presença diária dos alunos no colegiado;

Como não havia horário definido para o atendimento aos alunos, o assistente administrativo do colegiado era interrompido diáriamente durante suas atividades rotineiras, principalmente na digitação de atas das reuniões do colegiado.

2. Sobrecarga de trabalho;

Dentre os três colegiados da Univasf, Campus de Senhor do Bonfim - BA, o Colegiado de Ciências da Natureza era o único que recebia novas turmas a cada semestre. Em varios momentos era possível ver que as demandas administrativas que chegavam ao colegiado estavam sobrecarregando o assistente adiminstrativo.

3. Falta de motivação;

$\mathrm{O}$ acúmulo de tarefas, obrigações e as cobranças geradas estavam desmotivando o assitente administrativo que por vez se queixava. 


\section{Conclusão}

A principal contribuição deste estudo é demostrar a importância de analisar como esta sendo feita a divisão de tarefas dentro dos colegiados acadêmicos, não só como fonte de informações, mas como criador de significados a respeito da relação saúde-trabalho.

Nas observações e entrevista no colegiado, foi possível compreender mais facilmente o funcionamento da intituição pública em todos os seus aspectos e peculiaridades, bem como a importância de melhorar sua gestão pública e de pessoas, visando atingir qualidade em todos os serviços realizados pela instituição.

Embora o estudo tenha sido feito com um servidor público, tendo-se limitado ao contexto de trabalho de um colegiado acadêmico, pode-se considerar a hipótese da relação com o serviço público em geral, não sendo exclusivo das instituições de ensino.

\section{Referências}

ABRUCIO, F. L. Os Avanços e os dilemas do modelo pós-burocrático: a reforma da administração pública à luz da experiência internacional recente. In: BRESSER P.; SPINK, P. (Org.). Reforma do estado e administração pública gerencial. Rio de Janeiro: Editora FGV, 1998, 314pp.

BARNES, R. M. Estudo de movimentos e de tempos: projeto e medida do trabalho. 6 ed. São Paulo: Edgar Blücher, 1977.

CASELlA, D. M. A. Administração pública. Webartigos, 2008. Disponível em: <http://www. webartigos.com/artigos/administracao-publica/7063/>. Acesso em: 11 fev. 2017.

CHIAVENATO, I. Introdução à Teoria Geral da Administração. 7 ed. Rio de Janeiro: Elsevier, 2004.

CRUZ, T. Sistemas, Organização \& Métodos. São Paulo: Atlas, 2002.

DI GIACOMO, W. A. O New Public Management no Canadá e a gestão pública contemporânea. Revista Interfaces Brasil/Canadá, n. 5, 2005.

FIGUEIREDO F. J. S.; OLIVEIRA T. R. C.; SANTOS A. P. M. Estudo de tempos em uma indústria e comércio de calçados e injetados LTDA. - XXXI Encontro Nacional de Engenharia de Produção. Belo Horizonte, MG, Brasil, 2011. 
GIL, A. C. Métodos e técnicas de pesquisa social. São Paulo: Atlas, 1991.

HOOD, C. The Art of the state: culture, rhetoric, and public management. New York: Oxford University Press Inc., 1998.

JÚNIOR, C.P. A medicina do Trabalho no Contexto Atual. In: VIEIRA, I.S. Manual de Saúde e Segurança do Trabalho. $3^{\text {a }}$ ed. Curitiba: Genesis Editora, 1996.

MARCONI, M. A.; LAKATOS, E. M. Metodologia científica. 6. ed. São Paulo: Atlas, 2011.

MATTAR, F. N. Pesquisa de Marketing. 2a ed. São Paulo: Atlas, 1999.

OSÓRIO, F. M. Novos rumos da gestão pública brasileira: dificuldades teóricas ou operacionais? Revista Eletrônica sobre a Reforma do Estado, n. 1, 2005.

PAES DE PAULA, A. P. Por uma nova gestão pública. Rio de Janeiro: FGV, 2005.

PEINADO, Jurandir \& GRAEML, A. R. Administração da produção: operações industriais e de serviços. Curitiba: UnicenP, 2007

ROCHA, L. O. Organização e Métodos. São Paulo: Atlas, 1998.

SECCHI, L. Modelos organizacionais e reformas da administração pública. Revista de Administração Pública, v. 43, n. 2, 2009.

TAYLOR, F.W. Princípios de administração científica. 8. ed. São Paulo: Atlas, 1990.

TRIVIÑOS, A. N. S. Introdução à pesquisa em ciências sociais: a pesquisa qualitativa em educação. São Paulo: Atlas, 1987.

YIN, Robert K. Estudo de caso: planejamento e métodos. 2. ed. Porto Alegre, Bookmann, 2001.

ZOGHBI, J. F. G.; MARTINS, J. E. P. Gestão do conhecimento e da informação em ambientes com elevado turnover na alta chefia: um estudo de caso em projetos de governo. In: CONGRESSO CONSAD DE GESTÃO PÚBLICA, 2 ed., Brasília (DF). Anais. Brasília: Consad, 2009.

\section{Como citar este artigo (Formato ABNT):}

CAFFÉ FILLHO, Hesler P.; SOUZA, Jairo dos S.; AMORIM, Ricardo de S. Como o acúmulo de Atividades Administrativas no Colegiado Acadêmico de Ciências da Natureza da UNIVASF Campus Senhor do Bonfim BA interfere na Produtividade do Servidor: Um Estudo de Caso. Id on Line Revista Multidisciplinar e de Psicologia, Julho de 2017, vol.11, n.36, p.78-92. ISSN: 1981-1179.

Recebido: 13.06 .2017

Aceito: 16.06 .2017 